\title{
Gallium-67 as a diagnostic tool in the evaluation of peripheral pulmonary lesions
}

\author{
B. T. 1 e ROUX and A. E. HOULDER \\ The Thoracic Surgical Unit, Wentworth Hospital, and the Department of Radiophysics, \\ Addington Hospital, Durban
}

\begin{abstract}
le Roux, B. T., and Houlder, A. E. (1974). Thorax, 29, 355-358. Gallium-67 as a diagnostic tool in the evaluation of peripheral pulmonary lesions. While Gallium-67 shows a high affinity for primary pulmonary tumours, benign pulmonary lesions also concentrate the isotope. In 50 consecutive patients in whom the diagnosis of pulmonary carcinoma was not achieved by other means, the exhibition of ${ }^{\text {ai }} \mathrm{Ga}$ showed a positive scan in 36 , of whom three, on histological evidence, certainly did not have a pulmonary carcinoma, and in three others radiographic diminution in the extent of the peripheral pulmonary lesion makes most unlikely the diagnosis of carcinoma. In seven of 14 patients in whom the scan was negative it was judged necessary to undertake surgical management. Scanning with ${ }^{67} \mathrm{Ga}$ may modify the extent of surgical resection in some with a negative scan but does not establish the diagnosis of carcinoma in those with a positive scan, is unsafe as a screening test on which to base the decision on the need for referral to a thoracic surgeon, and in particular does not distinguish between the three common causes of 'chronic lung abscess'-chronic destructive pneumonia, cavitated carcinoma, and tuberculosis with cavitation and without tubercle bacilli in the sputum.
\end{abstract}

Gallium-67 is a cyclotron-produced isotope which in a carrier-free form has been shown to have a high affinity for malignant tissues which appears to be independent of histological type. The initial studies of ${ }^{67} \mathrm{Ga}$ were performed by Bruner, Hayes, and Perkinson (1953) as part of an attempt to use gallium isotope for specific therapy of bone tumours. It was while scanning the bones of a patient with Hodgkin's disease that the tumourspecific properties of ${ }^{67} \mathrm{Ga}$ citrate were discovered. Edward and Hayes $(1969 ; 1970)$ and, since that time, numerous others have confirmed the tumour-specific properties of this isotope. Reports concerning the uptake of ${ }^{67} \mathrm{Ga}$ citrate in primary lung cancer show that the detection efficiency is greater than $90 \%$.

However, benign lesions in the lungs also concentrate ${ }^{87} \mathrm{Ga}$ citrate. Positive scans have been obtained in active pulmonary tuberculosis, silicosis, acute infections, and especially with recently developed sarcoid. Healed tuberculosis, chronic infections, bacterial and viral pneumonias, pulmonary infarction, and pleural lesions generally give negative results. van der Schoot, van Marlevan der Goot, Groen, and de Jong (1972) found a positive scan in almost $40 \%$ of 58 cases with established benign pulmonary lesions.

The purpose of this paper is to report a study of the use of ${ }^{\text {gi }} \mathrm{Ga}$ in 50 consecutive patients. The objects of the trial were:

1. to confirm the high detection efficiency of ${ }^{67} \mathrm{Ga}$ in primary pulmonary tumours;

2. to evaluate its use in a series of patients in whom the chest radiograph showed a lesion of 'coin' type and in whom sputum had been shown not to contain tubercle bacilli;

3. to determine whether the routine use of ${ }^{67} \mathrm{Ga}$ as a diagnostic tool in the evaluation of 'peripheral' pulmonary lesions increased the accuracy of preoperative diagnosis, so as not only to modify the extent of pulmonary resection but also possibly to obviate the need for an aggressive surgical approach.

The trial was limited to 50 patients in whom the diagnosis of pulmonary carcinoma was not achieved by other means. It follows that most had peripheral, spherical, pulmonary opacities, some cavitated. In only one patient had tumour cells been demonstrated in a single specimen of sputum. In all but two patients the appearances at bron- 
T A B L E

\begin{tabular}{|c|c|c|c|c|c|c|c|c|c|c|c|c|}
\hline \multirow{2}{*}{\multicolumn{2}{|c|}{ Group }} & \multirow{3}{*}{$\begin{array}{c}\text { Age (yr) } \\
<30 \\
31-40 \\
41-50 \\
51-60 \\
61-70 \\
\end{array}$} & \multicolumn{2}{|c|}{ Caucasian } & \multicolumn{2}{|c|}{ Mulatto } & \multicolumn{2}{|c|}{ Asiatic } & \multicolumn{2}{|c|}{ African } & \multirow{2}{*}{\multicolumn{2}{|c|}{ Total }} \\
\hline & & & $\mathbf{M}$ & $F$ & $\mathbf{M}$ & $\mathbf{F}$ & M & F & M & $F$ & & \\
\hline $\mathbf{A}$ & $\begin{array}{l}\text { Positive }{ }^{67} \mathrm{Ga} \text { scan with } \\
\text { histological confirmation } \\
\text { of the diagnosis of carcinoma }\end{array}$ & & $\begin{array}{l}1 \\
1 \\
3\end{array}$ & 1 & & & 1 & & $\begin{array}{l}2 \\
4 \\
1 \\
1\end{array}$ & 1 & $\begin{array}{l}0 \\
3 \\
7 \\
7 \\
2 \\
4\end{array}$ & 16 \\
\hline B & $\begin{array}{l}\text { Positive }{ }^{67} \mathrm{Ga} \text { scan. } \\
\text { Diagnosis of carcinoma } \\
\text { likely on clinical grounds. } \\
\text { No histological confirmation }\end{array}$ & $\begin{array}{l}<30 \\
31-40 \\
41-50 \\
51-60 \\
61-70\end{array}$ & $\begin{array}{l}1 \\
1 \\
2\end{array}$ & $\begin{array}{c}1 \\
1(72)\end{array}$ & & & & & $\begin{array}{l}2 \\
4 \\
2\end{array}$ & & $\begin{array}{l}0 \\
0 \\
4 \\
5 \\
5\end{array}$ & 14 \\
\hline $\mathrm{C}$ & $\begin{array}{l}\text { Positive }{ }^{67} \mathrm{Ga} \text { scan. } \\
\text { Lesion shown histologically } \\
\text { ( } 3 \text { patients) or presumed on } \\
\text { radiological evidence } \\
\text { ( } 3 \text { patients) not to be a } \\
\text { carcinoma }\end{array}$ & $\begin{array}{l}<30 \\
31-40 \\
41-50 \\
51-60 \\
61-70\end{array}$ & & & & & & & $\begin{array}{l}2 \\
2 \\
1\end{array}$ & 1 & $\begin{array}{l}0 \\
3 \\
2 \\
1 \\
0\end{array}$ & 6 \\
\hline \multirow[t]{2}{*}{ D } & $\begin{array}{l}\text { Negative }{ }^{87} \mathrm{Ga} \text { scan. } \\
\text { Diagnosis of carcinoma } \\
\text { excluded on histological } \\
\text { evidence or reasonable } \\
\text { clinical grounds }\end{array}$ & $\begin{array}{l}<\quad 30 \\
31-40 \\
41-50 \\
51-60 \\
61-70\end{array}$ & $\frac{1}{2}$ & & \multicolumn{2}{|c|}{$1(21)$} & $\begin{array}{l}1 \\
1\end{array}$ & 1 & $\begin{array}{l}1 \\
1 \\
4\end{array}$ & & $\begin{array}{l}1 \\
2 \\
2 \\
7 \\
2\end{array}$ & 14 \\
\hline & & Total & 12 & 3 & 2 & - & 3 & 1 & 27 & 2 & & 50 \\
\hline
\end{tabular}

Males 44; Females 6

choscopy were normal. In two, each with the radiographic appearance of shrinkage of the left upper lobe, the left upper bronchus was seen at bronchoscopy to be compressed, but the mucosa looked normal and a biopsy from within the compressed bronchus showed normal bronchial epithelium.

The age range and sex of the patients are shown in the Table. In this the patients are grouped according to the final assessment of the results of the scan and not in the order in which they were investigated. Most (44) were men. The youngest was a mulatto male of 21 years and the oldest a Caucasian female of 72 . All but nine patients were older than 40 years; 11 were older than 60 and 32 were in the fifth and sixth decades. The race groups are represented in a more or less proper local proportion - there is a slight emphasis on Caucasians.

\section{METHOD}

${ }^{6:} \mathrm{Ga}$ citrate was injected intravenously with an approximate dose of $35 \mu \mathrm{Ci}$ per kilogram ( 2 to $3 \mathrm{mCi}$ per adult). ${ }^{67} \mathrm{Ga}$ decays by electron capture with a half-life of 78 hours yielding no beta rays. The gamma ray energies are $93 \mathrm{KeV}(40 \%), 184 \mathrm{KeV}(24 \%)$, $296 \mathrm{KeV}(22 \%)$, and $388 \mathrm{KeV}(7 \%)$. The 184 and $296 \mathrm{KeV}$ gamma rays are used for imaging purposes. Scanning was carried out at 48 hours after the injection of the dose, using a rectilinear colour scanner with 5-inch crystal. Only the anterior or the posterior surface of the chest was normally scanned.

\section{RESULTS}

Of the 50 patients the ${ }^{67} \mathrm{Ga}$ scan was positive in 36 and negative in 14 . In 16 patients (group A) $\frac{\circ}{\triangleright}$ with a positive ${ }^{67} \mathrm{Ga}$ scan the diagnosis of a malig- $\frac{\mathrm{O}}{\vec{B}}$ nant tumour was confirmed by pulmonary resec- $\overrightarrow{\overrightarrow{0}}$ tion or some other form of surgical manoeuvre which allowed of biopsy. In one patient the tumour was mediastinal and a reticulum-cell sarcoma; in 15 the tumour was a pulmonary car- $\overrightarrow{\overrightarrow{0}}$ cinoma-squamous in eight, an adenocarcinoma @ in three, and undifferentiated in four (called oat- $-\dot{-}$ cell in one of these). Pneumonectomy was under- 3 . taken in six patients and a lobectomy in four. In one patient with a squamous carcinoma tumour cells had been found on examination of one speci-o men of sputum, a finding which could not be repeated. In the patient with the mediastinalo lymphoma the diagnosis was achieved at mediastinoscopy. Formal thoracotomy was under- $\sigma$ taken in 12 patients in this group of 16 , and in the $N$ remaining four a diagnosis was achieved histo-N logically as a preliminary to a form of treatmento alternative to pulmonary resection because it waso recognized that the diagnosis of tumour was virtu- $\frac{\Gamma}{\Phi}$ ally certain and that this had extended beyond the $\stackrel{\mathcal{O}}{+}$ limits of surgical management.

In 14 patients (group B) in whom the ${ }^{67} \mathrm{Ga} \operatorname{scan} \frac{\overrightarrow{\mathrm{O}}}{\mathrm{O}}$ was positive, the diagnosis of carcinoma seems inescapable despite absence of histological con- $\varrho$ firmation. In three of these 14 patients the tumour was of the Pancoast variety and associated witho 
radiographic evidence of rib destruction. One patient with a left peripheral tumour was hoarse of voice; in two others there was gross oesophageal displacement, also accepted as evidence of mediastinal invasion. Three, who on all counts were suitable for surgical management, declined thoracotomy; a fourth had such severe angina that management by irradiation was preferred and the lesion has been seen to diminish; four were so frail that they were judged unsuitable for any form of management. The three with radiographic evidence of parietal invasion, the three with mediastinal invasion, and the one with angina whose lesion has regressed with irradiation certainly have pulmonary tumours, and, on all clinical criteria, these are primarily pulmonary. The three who continue to decline thoracotomy and the four too frail for surgical, or other, management would be regarded, on all available evidence, as having primary pulmonary malignant tumours, and growth of the primary lesion observed in four of these seven over the past six months tends further to substantiate the diagnosis.

In one patient in group B a large left peripheral pulmonary shadow, abutting on the chest wall and associated with medial rib erosion, has been shown by percutaneous aspiration biopsy to be a squamous carcinoma. In this patient there is an additional contralateral $2 \mathrm{~cm}$ peripheral pulmonary opacity presumed on radiological grounds to represent a pulmonopulmonary metastasis. The large left-sided lesion showed a strongly positive ${ }^{67} \mathrm{Ga}$ scan; the small right lesion did not. Medial chest wall invasion was the contra-indication to surgical management. On clinical grounds the right-sided lesion would, in the absence of contralateral medial chest wall invasion, have been accepted as evidence of haematogenous metastasis and therefore a contra-indication to management by left thoracotomy. The negative right-sided scan is judged on this evidence to represent failure of the metastasis either to take up ${ }^{87} \mathrm{Ga}$ or, because of size, to be demonstrable by the scanning technique used.

In six patients (group C), each with a positive ${ }^{67} \mathrm{Ga}$ scan, there is histological (in three) or radiographic (in three) evidence that the lesion is not a carcinoma. In two, the resected lesion was shown to be a chronic destructive pneumonia (chronic pyogenic lung abscess) and in the third the resected lesion was caseating tuberculosis, which was radiographically ingravescent despite a well-supervised four-week course of antituberculosis chemotherapy. Rapid diminution of a right upper pulmonary cavity in response to chemotherapy and physiotherapy makes the diagnosis of carcinoma most unlikely in a fourth, in whom bronchoscopic appearances were normal; in the remaining two, who have bronchoscopically normal bronchi, non-cavitated pulmonary opacities are diminishing slowly and are judged, on radiographic grounds, unlikely to represent carcinomata. In these last-mentioned two the evidence is presumptive and inconclusive but it has been judged on clinical and radiographic grounds unnecessary to proceed to diagnostic thoracotomy, despite the positive ${ }^{67} \mathrm{Ga}$ scan.

In 14 patients (group D) the results of scanning after the exhibition of ${ }^{67} \mathrm{Ga}$ were negative. Seven of these 14 patients were submitted to thoracotomy because of a well-defined peripheral pulmonary opacity, cavitated in one. In three patients the lesion was an hydatid cyst; in two the lesion was tuberculoma; in one a chondroadenoma (hamartoma); and in the last a 'plasma-cell granuloma'. In four of these patients the lesions were enucleated. In three-one an effete infected hydatid, another the 'plasma-cell granuloma', and the third a cavitated tuberculous lesion which was radiographically ingravescent despite good drug therapy-management was by lobectomy in the belief that the lesion was probably a carcinoma despite the negative scan. If cognisance had been taken of the negative scan two of these lesions could probably have been managed successfully by enucleation or subsegmental resection. The cavitated tuberculous lesion occupied most of the right upper lobe. In the remaining seven patients response in two to antituberculosis chemotherapy and in three to other forms of chemotherapy make certain the diagnosis of a tuberculous or other inflammatory lesion. The remaining two patients are elderly and frail and on general grounds unsuitable for surgical management. One has multiple lesions and has been known in the past to have tuberculosis and these lesions are probably tuberculous. The final diagnosis in these two patients is uncertain.

\section{DISCUSSION}

There are a number of reports concerning the uptake of ${ }^{67} \mathrm{Ga}$ in lung cancer. Langhammer et al. (1972) reviewed the results of four European university centres, Amsterdam, Berlin, Giessen, and Munich, where striking tumour concentration of ${ }^{\text {e7 }} \mathrm{Ga}$ was found in 62 of 70 patients with bronchial carcinoma. (In a previous communication van der Schoot et al. (1971) from Amsterdam 
University reported on $92 \%$ positive ${ }^{87} \mathrm{Ga}$ scans in bronchial carcinoma in 48 out of 54 cases.) Merrick et al. (1972) found gallium concentrated in all primary lung cancers in 21 patients. Higasi et al. (1972) found that all but one of 19 primary lung cancers showed positive scans, the size of the tumour missed being a $2 \times 1.5 \mathrm{~cm}$ adenocarcinoma. At Tohoku University, Ito et al. (1971) found that 21 out of 21 cases of pulmonary cancer were positive with ${ }^{67} \mathrm{Ga}$ scanning. These results indicate that ${ }^{67} \mathrm{Ga}$ is taken up in almost all primary pulmonary cancers; lesions which have been missed may be too small. These facts are undisputed. But does the exhibition of ${ }^{87} \mathrm{Ga}$ in any way modify the surgical attitude towards an isolated peripheral pulmonary lesion in a patient in whom the use of alternative diagnostic aids has failed to provide an answer and a sufficient period of time has been allowed to elapse to give inflammatory lesions the opportunity to regress? Is a positive scan unequivocal evidence for a diagnosis of carcinoma? Does a negative scan exonerate the surgeon from an aggressive approach? Is the easily available technique of scanning with ${ }^{67} \mathrm{Ga}$ one which may be used by physicians as a screening test on which to base the decision on whether to submit a patient for thoracic surgical opinion?

The analysis of the results of scanning after the exhibition of ${ }^{\text {ai }} \mathrm{Ga}$ in 50 consecutive patients makes clear that the answer to all these questions is an unequivocal no. Surgical attitude is unmodified by the use of ${ }^{87} \mathrm{Ga}$ additional to other routine diagnostic aids; the extent of surgical resection may occasionally be modified if the ${ }^{67} \mathrm{Ga}$ scan is negative and frozen section examination is available at the time of thoracotomy; a negative scan does not obviate the need for thoracotomy; it may be that a lesion which does not show a positive scan with gallium is in fact a carcinoma; and a positive scan is not in itself evidence of carcinoma. In particular, ${ }^{67} \mathrm{Ga}$ failed to distinguish between the three common local

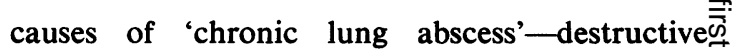
pneumonia, cavitated carcinoma, and tuberculosis without tubercle bacilli in the sputum.

\section{REFERENCES}

Bruner, H. D., Hayes, R. L., and Perkinson, J. D. (1953). Preliminary data on gallium-67. Radio$\log y, 61,602$.

Edwards, C. L. and Hayes, R. L. (1969). Tumor $\vec{\omega}$ scanning with gallium-67 citrate. Journal of Nuclear Medicine, 10, 103.

_- and (1970). Scanning malignant neoplasm with gallium-67. Journal of the Americariw Medical Association, 212, 1182.

Higasi, T., Nakayama, Y., Murata, A., Nakamura, K., 心 Sugiyama, M., Kawaguchi, T., and Suzuki, S.은 (1972). Clinical evaluation of gallium-67 citrate scanning. Journal of Nuclear Medicine, 13, 196.

Ito, Y., Okuyama, S., Awano, T., Takahashi, K. Sato, T., and Kanno, I. (1971). Diagnostic_ evaluation of gallium-67 scanning of lung cancere and other disease. Radiology, 101, 355.

Langhammer, H., Galubitt, G., Grebe, S. F., Hampe, J. F., Haubold, U., Hör, G., Kaul, A., Koeppe, P., Koppenhagen, J., Roedler, H. D., and van der Schoot, J. B. (1972). Gallium-67 forō tumor scanning. Journal of Nuclear Medicine? 13, 25 .

Merrick, M. V., Gunasekera, S. W., Lavender, J. P. Nunn, A. D., Thakur, M. L., and Williams, E. D. (1972). The use of indium-111 for tumour localization. International Atomic Energy Agency.

van der Schoot, J. B., Groen, A. S., and De Jong, J (1971). Gallium-67 scintigraphy in lung disease. 2nd Congress of the European Association of Radiology.

, van Marle-van der Goot, M., Groen, A. S. $\overline{0}$ and De Jong, J. (1972). Symposium on medica? radioisotope scintigraphy. Gallium-67 scintigraphyo in benign lung disease. International Atomic Energy Agency.

Requests for reprints to: Professor B. T. le Roux, The Thoracic Surgical Unit, Wentworth Hospital, Durban. 